\title{
RESEARCH CONCERNING THE SIMULATION OF THE OPERATION OF CONVENTIONAL SUCKER ROD PUMPING UNITS
}

\section{Georgeta Toma ${ }^{1}$}

${ }^{1}$ Universitatea Petrol-Gaze din Ploieşti, România

e-mail: georgeta_tm@yahoo.com;

\section{DOI: 10.51865/JPGT.2021.02.04}

\begin{abstract}
In the paper is presented a method for obtaining the variation during a cinematic cycle of the motor torque at the crankshaft in the case of the conventional sucker rod pumping units. The calculation method has been transposed into a computer program which allows establishing the influence of different constructive and operating parameters of the pumping units on the variation of the motor torque at the crankshaft. Finally, a series of results of the simulations performed in the case of a C-640D-305-120 pumping unit are presented.
\end{abstract}

Keywords: pumping units, motor torque, balancing, inertia forces and moments

\section{INTRODUCTION}

It is well known that conventional sucker rod pumping units are used intensively in oil extraction, so the study of their optimal operation represents a topical issue [1-10]. On the other hand, the study of the kinematics and dynamics of the mechanism of these pumping units is part of a broader issue specific to the theory of mechanisms and machines [11-19]. This paper presents a method for obtaining the variation during a cinematic cycle of the motor torque at the crankshaft in the case of the conventional sucker rod pumping units. A computer program which allows establishing the influence of different constructive and operating parameters of the pumping units on the variation of the motor torque at the crankshaft has been developed. Some simulations results obtained in the case of a C-640D-305-120 pumping unit are finally presented.

\section{THEORETICAL CONSIDERATIONS AND SIMULATION RESULTS}

In Figure 1 is represented the mechanism of a conventional sucker rod pumping unit. The positional and cinematic analysis of this mechanism may be accomplished with the method of projecting the closed and independent vector contours [20].

By projecting the vector equation: $\overline{O A}+\overline{A B}+\overline{B C}+\overline{C O}=0$ (Figure 1) on $(O x)$ and $(O y)$ axes the following system of equations is obtained:

$\left\{\begin{array}{l}l_{1} \cdot \cos \varphi_{1}+l_{2} \cdot \cos \varphi_{2}+l_{3} \cdot \cos \varphi_{3}-x_{C}=0 \\ l_{1} \cdot \sin \varphi_{1}+l_{2} \cdot \sin \varphi_{2}+l_{3} \cdot \sin \varphi_{3}-y_{C}=0\end{array}\right.$ 
where: $l_{1}=O A, l_{2}=A B$ and $l_{3}=B C$.

By solving the system of equations (1), the angles $\varphi_{2}$ and $\varphi_{3}$ may be calculated from the following relations:

$$
A_{2} \cdot \cos \varphi_{2}+B_{2} \cdot \sin \varphi_{2}=C_{2}
$$

where:

$$
\begin{aligned}
& \left\{\begin{array}{l}
A_{2}=2 \cdot l_{1} \cdot l_{2} \cdot \cos \varphi_{1}-2 \cdot l_{2} \cdot x_{C} \\
B_{2}=2 \cdot l_{1} \cdot l_{2} \cdot \sin \varphi_{1}-2 \cdot l_{2} \cdot y_{C} \\
C_{2}=l_{3}^{2}-l_{1}^{2}-l_{2}^{2}-x_{C}^{2}-y_{C}^{2}+2 \cdot l_{1} \cdot x_{C} \cdot \cos \varphi_{1}+2 \cdot l_{1} \cdot y_{C} \cdot \sin \varphi_{1}
\end{array}\right. \\
& \varphi_{3}=\operatorname{ATAN} 2\left(-\frac{1}{l_{3}}\left(l_{1} \cdot \sin \varphi_{1}+l_{2} \cdot \sin \varphi_{2}-y_{C}\right),-\frac{1}{l_{3}}\left(l_{1} \cdot \cos \varphi_{1}+l_{2} \cdot \cos \varphi_{2}-x_{C}\right)\right)
\end{aligned}
$$

where: $\operatorname{ATAN} 2(y, x)$ calculates $\arctan (y / x)$ by taking into account the signs of $x$ and $y$.

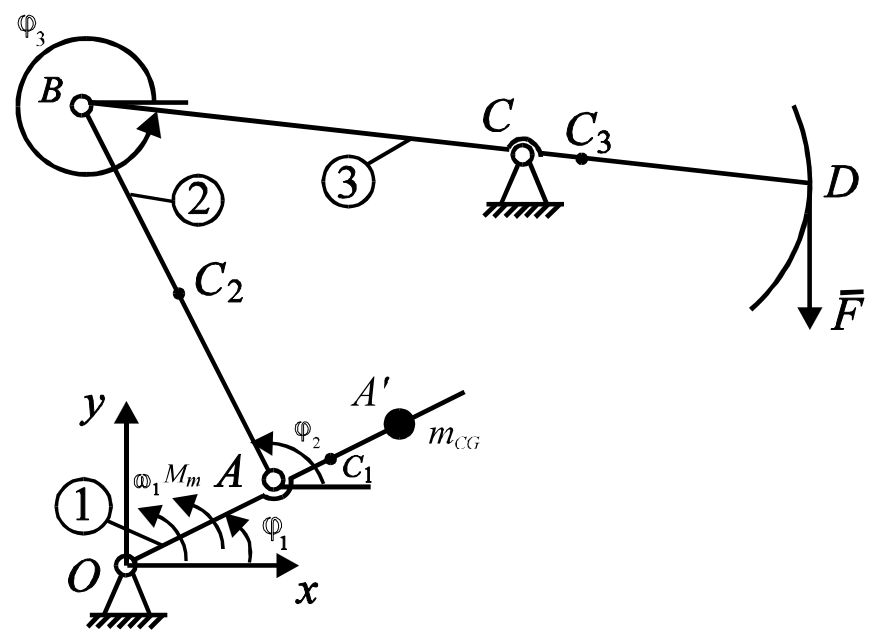

Figure 1. The mechanism of a conventional pumping unit

The angular speeds $\omega_{j}, j=2,3$, may be calculated as follows:

$$
\omega_{j}=\dot{\varphi}_{j}=\frac{\mathrm{d} \varphi_{j}}{\mathrm{~d} \varphi_{1}} \cdot \frac{\mathrm{d} \varphi_{1}}{\mathrm{~d} t}=\omega_{1} \cdot \frac{\mathrm{d} \varphi_{j}}{\mathrm{~d} \varphi_{1}} ; j=2,3
$$

where: $\omega_{1}$ is the angular speed of the cranks. By considering that $\omega_{1}$ is constant during the pumping unit operation, the angular accelerations $\varepsilon_{j}, j=2,3$, may be calculated as follows:

$$
\varepsilon_{j}=\dot{\omega}_{j}=\frac{\mathrm{d}^{2} \varphi_{j}}{\mathrm{~d} \varphi_{1}^{2}} \cdot \omega_{1}^{2} ; j=2,3
$$


The coordinates of the mass centers $C_{i}, i=1,2,3$, corresponding to the cranks, connecting rods and to the rocker may be calculated with the relations:

$$
\left\{\begin{array}{l}
x_{C_{1}}=O C_{1} \cdot \cos \varphi_{1} ; \quad y_{C_{1}}=O C_{1} \cdot \sin \varphi_{1} \\
x_{C_{2}}=O A \cdot \cos \varphi_{1}+A C_{2} \cdot \cos \varphi_{2} ; \quad y_{C_{2}}=O A \cdot \sin \varphi_{1}+A C_{2} \cdot \sin \varphi_{2} \\
x_{C_{3}}=O A \cdot \cos \varphi_{1}+A B \cdot \cos \varphi_{2}+B C_{3} \cdot \cos \varphi_{3} \\
y_{C_{3}}=O A \cdot \sin \varphi_{1}+A B \cdot \sin \varphi_{2}+B C_{3} \cdot \sin \varphi_{3}
\end{array}\right.
$$

The projections on $(O x)$ and $(O y)$ axes of the speeds and of the accelerations of the mass centers $C_{i}, i=1,2,3$, by considering that $\omega_{1}$ is constant during the pumping unit operation, may be calculated as follows:

$$
\begin{aligned}
& \left(v_{C_{i}}\right)_{x}=\dot{x}_{C_{i}}=\frac{\mathrm{d} x_{C_{i}}}{\mathrm{~d} \varphi_{1}} \cdot \frac{\mathrm{d} \varphi_{1}}{\mathrm{~d} t}=\omega_{1} \cdot \frac{\mathrm{d} x_{C_{i}}}{\mathrm{~d} \varphi_{1}} ; i=1,2,3 \\
& \left(v_{C_{i}}\right)_{y}=\dot{y}_{C_{i}}=\frac{\mathrm{d} y_{C_{i}}}{\mathrm{~d} \varphi_{1}} \cdot \frac{\mathrm{d} \varphi_{1}}{\mathrm{~d} t}=\omega_{1} \cdot \frac{\mathrm{d} y_{C_{i}}}{\mathrm{~d} \varphi_{1}} ; i=1,2,3 \\
& \left(a_{C_{i}}\right)_{x}=\ddot{x}_{C_{i}}=\frac{\mathrm{d}^{2} x_{C_{i}}}{\mathrm{~d} \varphi_{1}^{2}} \cdot \omega_{1}^{2} ; i=1,2,3 \\
& \left(a_{C_{i}}\right)_{y}=\ddot{y}_{C_{i}}=\frac{\mathrm{d}^{2} y_{C_{i}}}{\mathrm{~d} \varphi_{1}^{2}} \cdot \omega_{1}^{2} ; i=1,2,3
\end{aligned}
$$

The motor torque $M_{m}$ at the crankshaft may be calculated by expressing the dynamic equilibrium in instantaneous powers corresponding to the weights of all the components of the pumping unit mechanism, to the inertia forces and moments and to the force $\bar{F}$ (Figure 1) acting at the polished rod:

$$
\bar{M}_{m} \cdot \bar{\omega}_{1}+\sum_{j=1}^{3} \bar{G}_{j} \cdot \bar{v}_{C_{j}}+\bar{G}_{C G} \cdot \bar{v}_{A^{\prime}}+\sum_{j=1}^{3} \bar{F}_{i j} \cdot \bar{v}_{C_{j}}+\bar{F}_{i C G} \cdot \bar{v}_{A^{\prime}}+\sum_{j=1}^{3} \bar{M}_{i j} \cdot \bar{\omega}_{j}+\bar{F} \cdot \bar{v}_{D}=0
$$

where: $\bar{G}_{j}, \bar{F}_{i j}, \bar{M}_{i j}, j=1,2,3$, are the weights, the inertia forces and the inertia moments corresponding to the cranks, connecting rods and to the rocker, respectively; $\bar{G}_{C G}, \bar{F}_{i C G}$ are the weight and the inertia force corresponding to the counterweights whose total mass is $m_{C G}$ (Figure 1); $\bar{v}_{A^{\prime}}$ is the speed of the point where the mass of the counterweights is considered to be concentrated (Figure 1); $\bar{v}_{D}$ is the speed of the point where the force $\bar{F}$ at the polished rod acting (Figure 1).

A computer program that simulates the operation of the mechanism of the conventional sucker rod pumping units has been developed. Some simulations results obtained in the case of a C-640D-305-120 pumping unit are presented below. The dimensions of the component elements are in this case as follows: $O A=0.762 \mathrm{~m} ; A B=3.391 \mathrm{~m}$; $B C=2.822 \mathrm{~m} ; C D=3.937 \mathrm{~m} ; O A^{\prime}=1.295 \mathrm{~m}$. 
The coordinates of point $C$ (Figure 1) are: $x_{C}=2.189 \mathrm{~m} ; y_{C}=3.505 \mathrm{~m}$. The total mass of the counterweights is $m_{C G}=4808 \mathrm{~kg}$ and the linear masses of the cranks, connecting rods and of the rocker are: $q_{1}=722 \mathrm{~kg} / \mathrm{m} ; q_{2}=34 \mathrm{~kg} / \mathrm{m}$ and $q_{3}=300 \mathrm{~kg} / \mathrm{m}$.

The crank angles $\varphi_{1 d}$ and $\varphi_{1 a}$ corresponding to the beginning of the upward and downward movements of the sucker rod column have the values $89^{\circ}$ and $267^{\circ}$, respectively. The manner of obtaining the values of the angles $\varphi_{1 d}$ and $\varphi_{1 a}$ is presented in [8]. In Figure 2 is presented the variation of the force $\bar{F}$ at the polished rod during a cinematic cycle, beginning with the angle $\varphi_{1 d}$, when the angular speed $\omega_{1}$ is equal to $6 \mathrm{rot} / \mathrm{min}$.

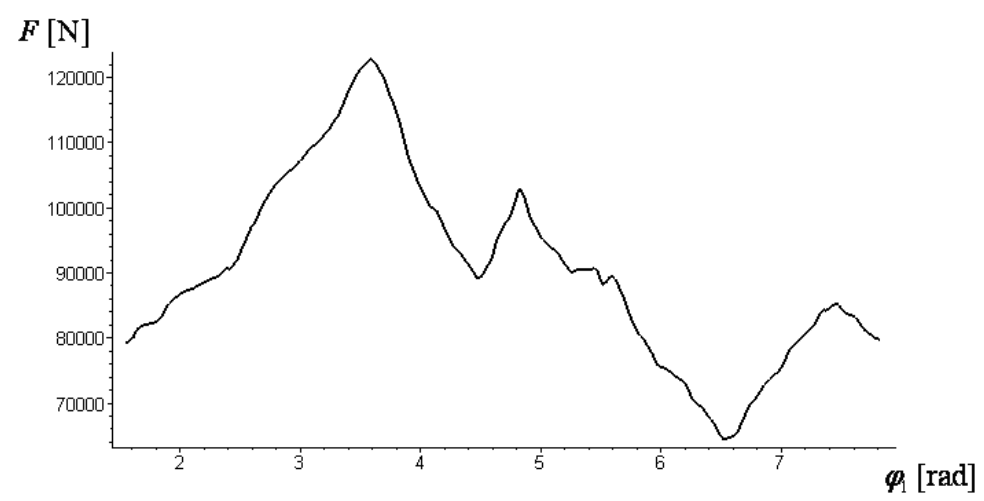

Figure 2. The variation of the force at the polished rod

In Figure 3 is represented the variation of the motor torque $M_{m}$ at the crankshaft during a cinematic cycle, beginning with the angle $\varphi_{1 d}$.

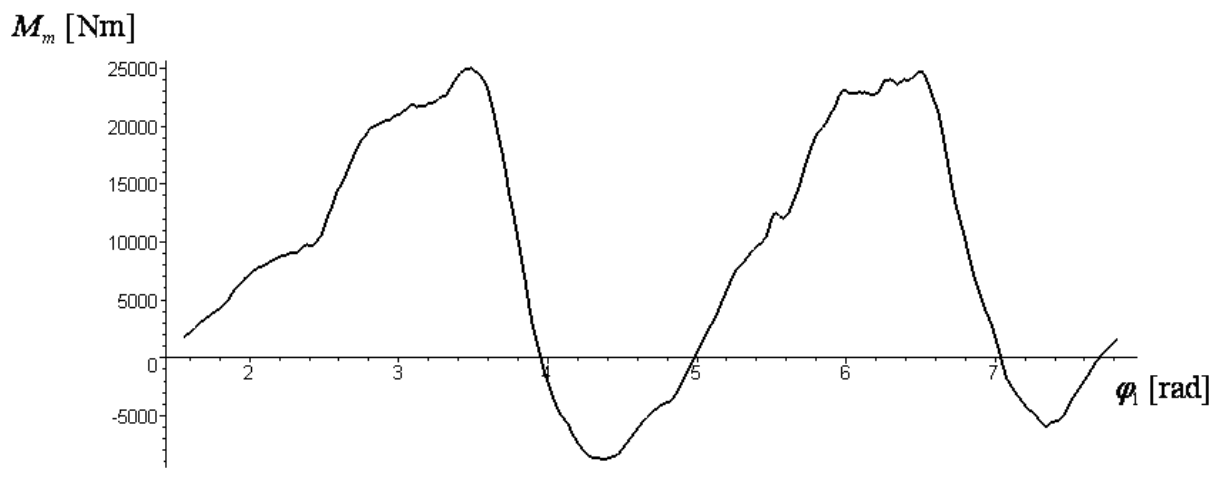

Figure 3. The variation of the motor torque at the crankshaft 
In Figure 4 is represented the variation of the moment $M_{m}^{G}$ due to the weights of the components: $M_{m}^{G}=-\frac{1}{\omega_{1}} \cdot\left(\sum_{j=1}^{3} \bar{G}_{j} \cdot \bar{v}_{C_{j}}+\bar{G}_{C G} \cdot \bar{v}_{A^{\prime}}\right)$ and in Figure 5 is represented the variation of the moment $M_{m}^{F}$ due to the force at the polished rod: $M_{m}^{F}=-\frac{1}{\omega_{1}} \cdot\left(\bar{F} \cdot \bar{v}_{D}\right)$.

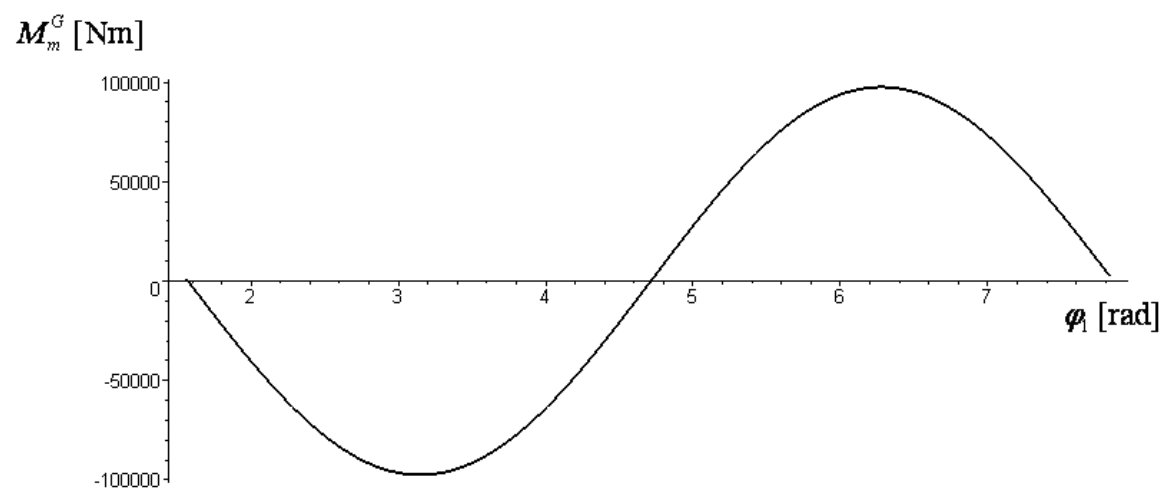

Figure 4. The variation of the moment $M_{m}^{G}$

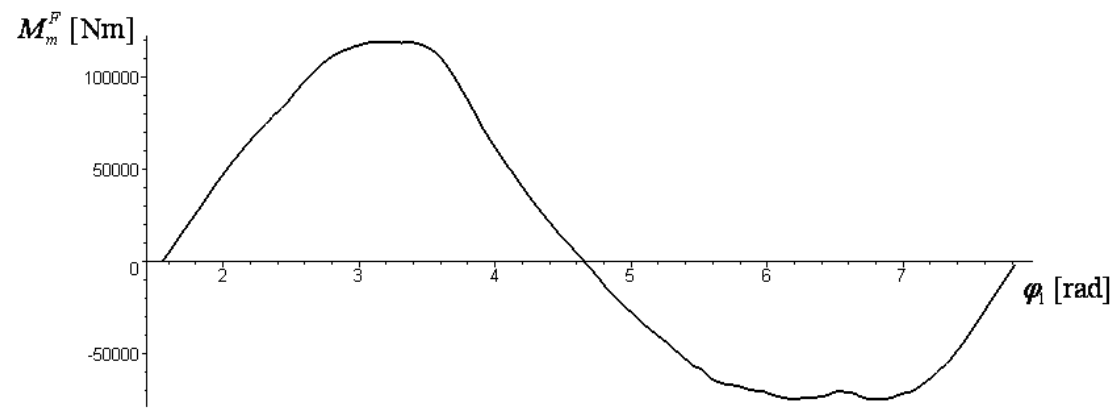

Figure 5. The variation of the moment $M_{m}^{F}$

In Figure 6 is represented the variation of the moment $M_{m}^{F_{i}}$ due to the inertia forces: $M_{m}^{F_{i}}=-\frac{1}{\omega_{1}} \cdot\left(\sum_{j=1}^{3} \bar{F}_{i j} \cdot \bar{v}_{C_{j}}+\bar{F}_{i C G} \cdot \bar{v}_{A^{\prime}}\right)$ and in Figure 7 is represented the variation of the moment $M_{m}^{M_{i}}$ due to the inertia moments: $M_{m}^{M_{i}}=-\frac{1}{\omega_{1}} \cdot\left(\sum_{j=1}^{3} \bar{M}_{i j} \cdot \bar{\omega}_{j}\right)$. 


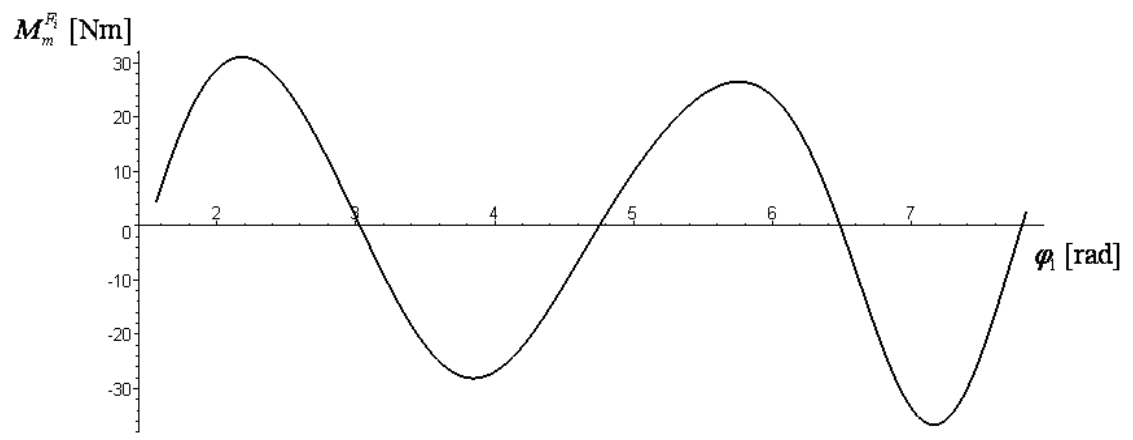

Figure 6. The variation of the moment $M_{m}^{F_{i}}$

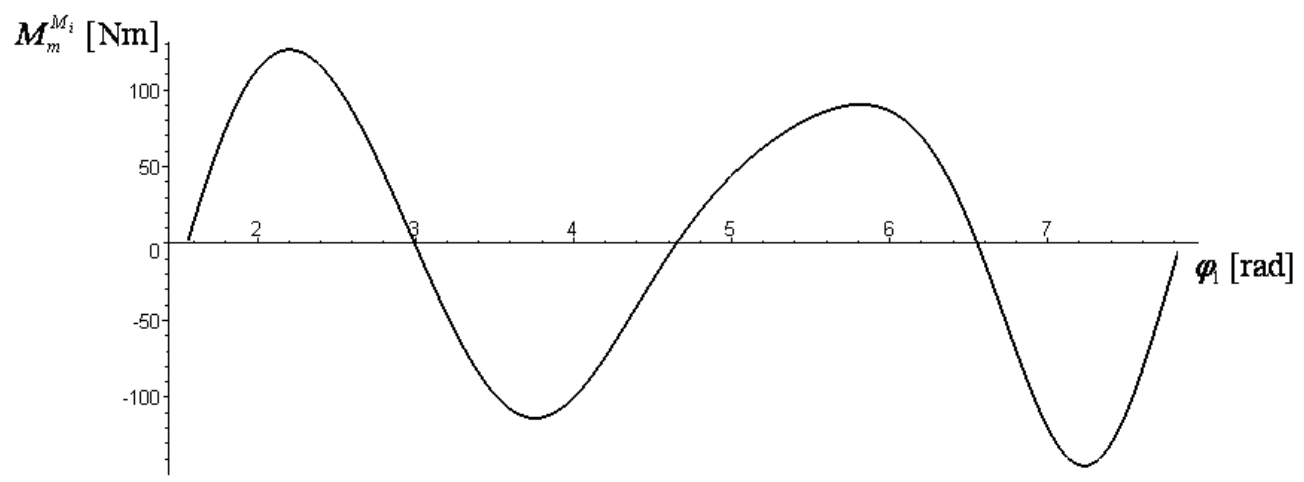

Figure 7. The variation of the moment $M_{m}^{M_{i}}$

\section{CONCLUSIONS}

In the paper has been presented a method for obtaining the variation during a cinematic cycle of the motor torque at the crankshaft in the case of the conventional sucker rod pumping units. A computer program which allows simulating the operation of the mechanism of the conventional sucker rod pumping units has been developed. The simulations results presented in the case of a C-640D-305-120 pumping unit showed that this one is well balanced. From the analysis of the contribution to the variation of the motor torque at the crankshaft resulted that most of it is due to the force at the polished rod and to the weight of the component elements, the influence of the inertia forces and inertia moments being negligible.

\section{REFERENCES}

[1]Badoiu D., Research concerning the movement equation of the mechanism of the conventional sucker rod pumping units, Revista de Chimie, Volume 70, Issue 7, pp. 2477-2480, 2019.

[2]Badoiu D., Research concerning the use of polynomial functions in the study of the conventional sucker rod pumping units, Revista de Chimie, Volume 70, Issue 4, pp. 1223-1227, 2019. 
[3]Badoiu D., Toma G., Research concerning the predictive evaluation of the motor moment at the crankshaft of the conventional sucker rod pumping units, Revista de Chimie, Volume 70, Issue 2, pp. 378-381, 2019.

[4]Badoiu D., Toma G., Research concerning the correlations between some experimental results in the case of a sucker rod pumping installation, Revista de Chimie, Volume 69, Issue 11, pp. 3060-3063, 2018.

[5]Badoiu D., Toma G., Research concerning the kinetostatic analysis of the mechanism of the conventional sucker rod pumping units, Revista de Chimie, Volume 69, Issue 7, pp. 1855-1859, 2018.

[6]Toma G., Pupazescu A., Badoiu D., Simulation of the sucker rod column dynamics for different pumping regimes, Revista de Chimie, Volume 68, Issue 11, pp. 2593-2596, 2017.

[7]Badoiu D., Toma G., Research concerning the identification of some parameters of a sucker rod pumping unit, Revista de Chimie, Volume 68, Issue 10, pp. 2289-2292, 2017.

[8]Toma G., Pupăzescu A., Bădoiu D., On the Kinematics of Some Sucker Rod Pumping Units, Petroleum-Gas University of Ploiesti Bulletin, Technical Series, Volume 66, Issue 3, pp. 95-100, 2014.

[9]Toma G., Pupăzescu A., Bădoiu D., On a Synthesis Problem of the Mechanism of a Sucker Rod Pumping Unit, Petroleum-Gas University of Ploiesti Bulletin, Technical Series, Volume 65, Issue 4, pp. 107-111, 2013.

[10] Bădoiu D., Toma G., Analysis of the dynamic response of the mechanism of conventional sucker rod pumping units, Revista de Chimie, Volume 71, Issue 1, pp. 395-399, 2020.

[11] Toma G., Bădoiu D., On the variation of the motor moment in the case of a total statically balanced quadrilateral mechanism, Petroleum-Gas University of Ploiesti Bulletin, Technical Series, Volume 69, Issue 1, pp. 69-74, 2017.

[12] Badoiu D., Toma G., On a dynamic optimisation problem of the quadrilateral mechanism, Journal of the Balkan Tribological Association, Volume 22, Issue 1, pp. 250-260, 2016.

[13] Bădoiu D., On the establishing and solving of the movement equation in the case of the plane mechanisms, Petroleum-Gas University of Ploiesti Bulletin, Volume 67, Issue 3, pp. 87-93, 2015.

[14] Bădoiu D., On the movement equation of the quadrilateral mechanism, PetroleumGas University of Ploiesti Bulletin, Volume 67, Issue 2, pp. 67-72, 2015.

[15] Toma G., Bădoiu D., Research concerning the calculus of the equilibrium moment in the case of a plane mechanism using the dynamic model, Petroleum-Gas University of Ploiesti Bulletin, Volume 67, Issue 2, pp. 93-98, 2015.

[16] Bădoiu D., On the calculus of the equilibrium moment for a mechanism with three independent contours, Petroleum-Gas University of Ploiesti Bulletin, Technical Series, Volume 67, Issue 1, pp. 99-104, 2015. 
[17] Bădoiu D., On the positional and cinematic analysis of a mechanism with three independent contours, Petroleum-Gas University of Ploiesti Bulletin, Technical Series, Volume 66, Issue 2, pp. 55-58, 2014.

[18] Bădoiu D., On the dynamic behavior of a quadrilateral mechanism, Petroleum-Gas University of Ploiesti Bulletin, Technical Series, Volume 64, Issue 2, pp. 39-42, 2012.

[19] Toma G., Bădoiu D., On the cinematic analysis of a mechanism of fourth class, Petroleum-Gas University of Ploiesti Bulletin, Technical Series, Volume 64, Issue 1, pp. 69-72, 2012.

[20] Badoiu D., Toma G., Structura si cinematica mecanismelor cu bare, Editura Universităţii Petrol-Gaze din Ploieşti, Ploieşti, 2019. 